\title{
Respiratory dysfunction in multiple sclerosis: a prospective analysis of 60 patients
}

\author{
B. Buyse*, M. Demedts*, J. Meekers**, L. Vandegaer**, F. Rochette*, L. Kerkhofs**
}

Respiratory dysfunction in multiple sclerosis: a prospective analysis of 60 patients. $B$. Buyse, M. Demedts, J. Meekers, L. Vandegaer, F. Rochette, L. Kerkhofs. @ERS Journals Ltd 1997.

ABSTRACT: This study aimed to determine the relationship between pulmonary function, respiratory muscle function and neurological function in multiple sclerosis (MS).

Sixty patients ( 27 males and 33 females) aged $27-75$ yrs (mean \pm sD $48 \pm 12$ yrs) were prospectively studied.

The Kurtzke Expanded Disability Status Scale (EDSS; range 0-10) score was 6.5 \pm 1.5 ; and the different Functional Systems Scores (FSS; ranges 0-5 and 0-6) were: pyramidal $3.4 \pm 1.1$; brain stem $1.9 \pm 1.2$; mental $1.3 \pm 0.9$; cerebellar $2.2 \pm 1.0$; sphincter 1.8 \pm 1.5 ; visual $1.4 \pm 1.4$; and sensory $2.0 \pm 1.5$. Results of lung function tests were: vital capacity (VC) $\mathbf{8 0} \pm 23 \%$ of predicted; single-breath transfer factor of the lung for carbon monoxide ( $T \mathrm{~L}, \mathrm{CO}, \mathrm{sb}) \mathrm{83} \pm 17 \%$ pred; maximal static expiratory mouth pressure (MEP) 30 $\pm 16 \%$ pred; and maximal static inspiratory mouth pressure (MIP) $47 \pm 23 \%$ pred, indicating a marked respiratory muscle dysfunction, with a minor restrictive defect. In $70 \%$ of the patients, a transcutaneous oxygen saturation $\left(\mathrm{Stc}_{2} \mathrm{O}_{2}\right)$ of less than $92 \%$ at night was found. Comparison of lung function and disability scores showed that the abnormalities in both tended to be correlated to each other, and that this was significant for EDSS versus lung volumes, for most FSS with VC, and also for some FSS with MEP and/or MIP. Duration of disease was significantly correlated with the EDSS, but not with the different FSS scores (with the exception of mental status) and not with lung function.

Multiple sclerosis leads to lung function abnormalities attributable to respiratory pump dysfunction.

Eur Respir J., 1997; 10: 139-145.
*Pulmonary Division, University Hospital Gasthuisberg, Leuven, Belgium. **Multiple Sclerosis and Revalidation Center, Overpelt, Belgium.

\section{Correspondence: B. Buyse}

Pulmonary Division

University Hospital Gasthuisberg

Herestraat 49

B-3000 Leuven

Belgium

Keywords: Disability score maximal mouth pressures multiple sclerosis

pulmonary function

respiratory muscles

Received: July 271995

Accepted after revision September 301996
Respiratory complaints are common in the terminal stage of multiple sclerosis (MS), and death is often due to bulbar weakness leading to aspiration and pneumonia. Respiratory involvement occurring earlier in the course of the disease is mostly due to reversible neuromuscular failure [1-10].

However, few data are available concerning the relationship between the severity of MS and the lung function abnormalities. The aim of the present study was, therefore, to examine in a more systematic prospective way the pulmonary function, including respiratory muscle and neurological function, in $60 \mathrm{MS}$ patients.

\section{Subjects and methods}

\section{Subjects}

Sixty consecutive hospitalized patients from a MS neurological and rehabilitation centre, meeting the criteria of Poser et al. [11] for the diagnosis of definite MS, were included. There were 27 males and 33 females, aged $27-75$ yrs (mean \pm sD $48 \pm 12 \mathrm{yrs}$ ), with body mass index (BMI) $($ mean $\pm \mathrm{SD})$ of $24 \pm 5 \mathrm{~kg} \cdot \mathrm{m}^{-2}$ (range $\left.15-37 \mathrm{~kg} \cdot \mathrm{m}^{-2}\right)$.
Fourteen patients were underweight $\left(\mathrm{BMI}<24 \mathrm{~kg} \cdot \mathrm{m}^{-2}\right)$ and five obese $\left(\mathrm{BMI}>30 \mathrm{~kg} \cdot \mathrm{m}^{-2}\right)$. Seven patients had a medical problem or history probably not related to MS: hypothyroidism (1); systemic hypertension (2); chronic bronchitis (2); and chronic obstructive pulmonary disease (COPD) (2). Polymedication was present in several patients: 25 patients used a benzodiazepine and/or an antidepressant or a neuroleptic and/or a morphine preparation.

\section{Clinical assessments}

Patients were interviewed by one of the research team (JM), with special emphasis on history of respiratory illness, tobacco use, and pulmonary symptoms. A chest radiograph could be performed in 40 patients (some refused it).

The Kurtzke Expanded Disability Status Scale (EDSS) and Functional Systems Score (FSS) [12] were used to describe levels of neurological functioning. The EDSS provides an overall score ranging from zero (indicating normal neurological findings) to 10 (indicating death from MS). The FSS yields specific information on the 
grade of involvement of the following neurological functions: pyramidal, sensory, cerebellar, brain stem, sphincter, visual and mental; these impairments are expressed with a score ranging $0-5$ or $0-6$. The scores were assigned by the neurologist (PV) without knowledge of the results of the subject's pulmonary function tests.

\section{Pulmonary function tests}

Pulmonary function tests included: static and dynamic spirometry (vital capacity (VC), forced expiratory volume in one second (FEV1), total lung capacity (TLC), residual volume $(\mathrm{RV})$ ); flow rates (peak expiratory flow (PEF), maximal expiratory flow when 50 and $75 \%$ of the VC has been exhaled (MEF50, MEF25)); plethysmographic volumes (TLC, thoracic gas volume (TGV), $\mathrm{RV})$; single-breath lungs for carbon monoxide ( $T \mathrm{~L}, \mathrm{CO}, \mathrm{sb})$; and airway resistance (Raw) and specific airway conductance ( $\mathrm{s} G \mathrm{aw})$. Maximal static expiratory and inspiratory mouth pressures (MEP and MIP) were measured according to techniques described previously [13-15]. Each patient performed at least three trials and the best performance was used for analysis. The measurements were carried out according to the criteria of the American Thoracic Society (ATS) and European Respiratory Society (ERS) [16-18]. The prediction equations of the ERS, which are representative for the European Community for Steel and Coal [17, 18], were used for lung volumes and $T \mathrm{~L}, \mathrm{CO}, \mathrm{sb}$. For $R$ aw, $0.22 \mathrm{kPa} \cdot \mathrm{L}^{-1}$.s was used as the reference value [17, 18]. The MEP and MIP were expressed as percentages of the predicted values of Rochester and ARORA [19], which were very similar to the normal values obtained in our laboratory $[13,14]$. All studies were performed in a sitting position in a Medgraphics System 1085/D Body Plethysmograph (Medical Graphics Corporation, St. Paul, MN, USA).

Nocturnal transcutaneous oxygen saturation $\left(\mathrm{Stc}, \mathrm{O}_{2}\right)$ was measured in 27 patients, using a pulse oximeter (Palco model 400; Palco Labs, Santa Cruz, USA). The patients were monitored through-out the whole night.

\section{Statistical analysis}

Mean \pm SD was calculated. Student's t-tests were applied for unpaired samples. Differences were considered significant at a p-value of less than 0.05 .

\section{Results}

\section{Medical history and pulmonary function}

Among the 52 patients of whom the smoking history was known, 17 were lifetime nonsmokers, 15 ex-smokers, and 20 current smokers. Eight patients did not answer the questionnaire about smoking habits. In 11 (of 58) patients, pulmonary symptoms were reported, such as cough and sputum, wheezing or shortness of breath. In the 40 patients in whom a chest radiograph was taken, no significant abnormalities were noted. Only two patients had known chronic obstructive lung disease and used bronchodilatators. Two other patients used mucolytics for chronic bronchitis.

The results (mean $\pm \mathrm{SD}$ ) of the different pulmonary function tests are presented in table 1 . Several pulmonary
Table 1. - Pulmonary function tests

\begin{tabular}{|c|c|c|c|}
\hline & $\begin{array}{c}\text { Pts } \\
\mathrm{n}\end{array}$ & Absolute value & $\%$ pred \\
\hline VC L & 60 & $3.0 \pm 1.4$ & $80 \pm 23$ \\
\hline TLC L & 35 & $5.6 \pm 1.5$ & $100 \pm 18$ \\
\hline RV L & 35 & $2.1 \pm 1.0$ & $115 \pm 51$ \\
\hline RV/TLC \% & 35 & $38 \pm 14$ & $113 \pm 38$ \\
\hline TGV L & 35 & $3.2 \pm 1.1$ & $107 \pm 30$ \\
\hline FEV1 L & 60 & $2.3 \pm 0.9$ & $76 \pm 25$ \\
\hline FEV1/VC \% & 60 & $75 \pm 14$ & $93 \pm 18$ \\
\hline PEF L & 60 & $4.6 \pm 1.7$ & $62 \pm 22$ \\
\hline MEF50 L & 60 & $2.8 \pm 1.3$ & $66 \pm 27$ \\
\hline MEF25 L & 60 & $1.3 \pm 0.9$ & $69 \pm 40$ \\
\hline$R$ aw $\mathrm{kPa} \cdot \mathrm{L}^{-1} \cdot \mathrm{s}$ & 35 & $0.27 \pm 0.14$ & $121 \pm 68$ \\
\hline sGaw $\mathrm{kPa}^{-1} \cdot \mathrm{s}^{-1}$ & 35 & $1.4 \pm 0.5$ & $142 \pm 58$ \\
\hline$T \mathrm{~L}, \mathrm{CO}, \mathrm{sb} \mathrm{mmol} \cdot \mathrm{min}^{-1} \cdot \mathrm{kPa}^{-1}$ & 53 & $7.5 \pm 2.0$ & $83 \pm 17$ \\
\hline $\mathrm{MEP} \mathrm{cmH}_{2} \mathrm{O}$ & 58 & $48 \pm 29$ & $30 \pm 16$ \\
\hline MIP $\mathrm{cmH}_{2} \mathrm{O}$ & 58 & $47 \pm 28$ & $47 \pm 23$ \\
\hline
\end{tabular}

Values are presented as mean \pm SD. Pts: patients; \% pred: percentage of predicted value; VC: vital capacity; TLC: total lung capacity; RV: residual volume; TGV: thoracic gas volume; FEV1: forced expiratory volume in one second; PEF: peak expiratory flow; MEF50 and MEF25: maximal expiratory flow when 50 and $75 \%$ of the $\mathrm{VC}$ has been exhaled; $R$ aw: airways resistance; sGaw: specific airways conductance; $T \mathrm{~L}, \mathrm{CO}$,sb: singlebreath transfer factor of the lungs for carbon monoxide; MEP and MIP: maximum static expiratory and inspiratory mouth pressure.

tests could not be performed in some patients because of neuromuscular problems, although all patients tried to participate. The mean values of VC were at the lower limit of normality and mean RV was at the upper limit. The mean values for FEV1, PEF, MEF50 and MEF25 were slightly reduced. Among the whole group of 60 patients, 11 patients presented an obstructive pattern, 13 a restrictive pattern, and 8 a mixed (obstructive and restrictive) pattern based on the VC, FEV1 and FEV1/VC values. Eleven of the 19 patients with an obstructive dysfunction were current or ex-smokers. Mean TLC (measurement only possible in 35 patients) was normal; it was increased in five patients (two with an obstructive spirometric defect and three with normal spirometric values), and was decreased in six patients (four with a restrictive or mixed spirometric defect, one with an obstructive spirometric defect, and one with normal spirometric values). The mean value for $T \mathrm{~L}, \mathrm{CO}, \mathrm{sb}$ was at the lower limit of normality. The TL,CO,sb was decreased in 18 out of 53 patients, and in six of them haemoglobin was decreased $\left(<12.5 \mathrm{~g} \cdot \mathrm{dL}^{-1}\right.$ for females and $<13$ $\mathrm{g} \cdot \mathrm{dL}^{-1}$ for men).

The mean value of MEP, and also to a lesser degree the mean value of MIP, were markedly reduced, thus showing clearcut respiratory muscle dysfunction. In fact, MEP was abnormal in 57 out of 58 patients and MIP in 49. The MEP values were significantly lower $(\mathrm{p}<0.002)$ in the group with a restrictive pulmonary function defect ( $\mathrm{VC}<80 \%$ pred) or mixed pulmonary function defect ( $\mathrm{VC}<80 \%$ pred; FEV1/VC $<65 \%$ ), than in those with normal lung volumes (table 2). Furthermore, MIP values were significantly lower $(p<0.05)$ in the patients with a restrictive function in comparison with the others.

In 27 unselected patients, nocturnal $S_{t c}, \mathrm{O}_{2}$ was measured. The alarm setting was installed at $92 \%$, and in 
Table 2. - Maximal respiratory pressures in multiple sclerosis (MS) patients with normal lung volumes, in comparison with MS patients with a restrictive disturbance

\begin{tabular}{lccc}
\hline & $\begin{array}{c}\text { Normal lung } \\
\text { volumes } \\
(\mathrm{n}=28)\end{array}$ & $\begin{array}{c}\text { Restrictive (or } \\
\text { mixed) function } \\
(\mathrm{n}=21)\end{array}$ & p-value \\
\hline MEP \% pred & $37 \pm 17$ & $22 \pm 14$ & $<0.002$ \\
MIP \% pred & $54 \pm 23$ & $38 \pm 14$ & $<0.05$ \\
\hline
\end{tabular}

MEP and MIP: maximal static expiratory and inspiratory mouth pressure, respectively; \% pred: percentage of predicted value.

19 of these patients $(70 \%)$ a $\mathrm{Stc}, \mathrm{O}_{2}$ of $92 \%$ or less was found. The number of desaturations $\left(\mathrm{Stc}, \mathrm{O}_{2}<92 \%\right)$ per night varied widely between the different patients (36 \pm 35 (range 1-110) episodes per night), and the duration of desaturation was $71 \pm 87$ (range 2-263 min). During these desaturation episodes, the mean $\mathrm{Stc}_{\mathrm{tc}} \mathrm{O}_{2}$ was $88 \pm 4 \%$ (range $75-92 \%$ ). As shown in table 3, pulmonary function generally tended to be worse in desaturators $(<92 \%$ at night) than in nondesaturators (with the exception of FEV1, TLC and TL,CO,sb), and the difference was significant for TGV, Raw and sGaw. Based on the VC, FEV1 and FEV1/VC values, 10 of the 19 desaturators had an abnormal spirometry (four had a restrictive defect, five a mixed defect, and one an obstructive disorder).
Neurological disability and relationship with pulmonary function

The overall Kurtzke EDSS score (from 0-10) ranged from 2.5 (minimal disability) to 8.5 (patient restricted to bed much of the day; has some effective use of arm(s); retains some self-care functions). The mean level of disability was $6.5 \pm 1.5$ (which reflects a need for continuous bilateral assistance with canes, crutches or braces in order to walk about 20 min without resting). Functional Systems Scores (FSS) were calculated for different subfunctions. The mean FSS was: $3.4 \pm 1.1$ (on 0-6 scale) for pyramidal function; $1.9 \pm 1.2$ (on $0-5$ ) for brain stem function; $1.3 \pm 0.9$ (on $0-5$ ) for mental function; $2.2 \pm 1.0$ (on $0-5$ ) for cerebellar function; $1.8 \pm 1.5$ (on $0-6$ ) for sphincter function; $1.4 \pm 1.4$ (on $0-6$ ) for visual

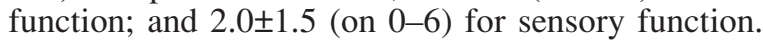

The patients were grouped according to two levels of EDSS disability: EDSS $<7$ (i.e. being ambulatory, some of them with assistance, but not wheelchair bound); and EDSS $\geq 7$ (i.e. being wheelchair bound or having an even worse neurological function) (table 4). All pulmonary function indices tended to be better in the less disabled patients, with a statistically significant difference for VC, FEV1, PEF and MEF50. In fact, all mean pulmonary function indices were normal in the

Table 3. - Pulmonary function tests in desaturators and nondesaturators (alarm limit at 92\%)

\begin{tabular}{|c|c|c|c|c|c|}
\hline & \multicolumn{2}{|c|}{ Desaturators } & \multicolumn{2}{|c|}{ Nondesaturators } & \multirow[b]{2}{*}{$\mathrm{p}$-value } \\
\hline & $\mathrm{n}$ & mean $\pm \mathrm{SD}$ & $\mathrm{n}$ & mean $\pm \mathrm{SD}$ & \\
\hline VC $\%$ pred & 19 & $77 \pm 26$ & 8 & $91 \pm 21$ & NS \\
\hline FEV1 \% pred & 19 & $77 \pm 27$ & 8 & $75 \pm 30$ & NS \\
\hline $\mathrm{FEV}_{1} / \mathrm{VC} \%$ pred & 19 & $98 \pm 17$ & 8 & $92 \pm 12$ & NS \\
\hline TLC $\%$ pred & 12 & $96 \pm 19$ & 6 & $97 \pm 13$ & NS \\
\hline RV \% pred & 12 & $121 \pm 54$ & 6 & $86 \pm 53$ & NS \\
\hline RV/TLC \% pred & 12 & $124 \pm 50$ & 6 & $91 \pm 37$ & NS \\
\hline TGV \% pred & 12 & $144 \pm 30$ & 6 & $96 \pm 29$ & $<0.05$ \\
\hline$R$ aw $\%$ pred & 12 & $137 \pm 57$ & 6 & $86 \pm 36$ & $<0.05$ \\
\hline sGaw \% pred & 12 & $105 \pm 56$ & 6 & $194 \pm 56$ & $<0.01$ \\
\hline$T \mathrm{~L}, \mathrm{CO}, \mathrm{sb} \%$ pred & 17 & $82 \pm 15$ & 8 & $76 \pm 15$ & NS \\
\hline MEP \% pred & 19 & $27 \pm 17$ & 8 & $35 \pm 22$ & NS \\
\hline MIP \% pred & 19 & $47 \pm 26$ & 8 & $52 \pm 23$ & NS \\
\hline
\end{tabular}

Ns: not significant. For further definitions see legend to table 1.

Table 4. - Disability score and pulmonary function

\begin{tabular}{lccccc}
\hline & \multicolumn{2}{c}{ EDSS $\geq 7$} & \multicolumn{2}{c}{ EDSS $<7$} & \\
\cline { 2 - 3 } & Mean \pm sD & $\mathrm{n}$ & Mean \pm sD & $\mathrm{n}$ & p-value \\
\hline VC \% pred & $72 \pm 24$ & 26 & $95 \pm 12$ & 18 & $<0.001$ \\
TLC \% pred & $96 \pm 20$ & 10 & $108 \pm 17$ & 16 & NS \\
RV \% pred & $101 \pm 43$ & 10 & $130 \pm 56$ & 16 & NS \\
RV/TLC \% pred & $121 \pm 48$ & 10 & $108 \pm 36$ & 16 & NS \\
TGV \% pred & $100 \pm 29$ & 10 & $117 \pm 35$ & 16 & $<0.002$ \\
FEV1 \% pred & $70 \pm 23$ & 26 & $91 \pm 18$ & 18 & NS \\
FEV1/VC \% pred & $91 \pm 17$ & 26 & $95 \pm 17$ & 18 & $<0.001$ \\
PEF \% pred & $55 \pm 21$ & 26 & $93 \pm 18$ & 18 & NS \\
MEF50 \% pred & $56 \pm 26$ & 26 & $76 \pm 28$ & 18 & NS \\
MEF25 \% pred & $67 \pm 42$ & 26 & $72 \pm 38$ & 18 & NS \\
Raw \% pred & $124 \pm 49$ & 9 & $111 \pm 66$ & 16 & NS \\
sGaw \% pred & $140 \pm 56$ & 9 & $92 \pm 62$ & 16 & N \\
TL,CO \% pred & $80 \pm 18$ & 9 & $34 \pm 11$ & 18 & NS \\
MEP \% pred & $26 \pm 16$ & 25 & $50 \pm 18$ & 18 & \\
MIP \% pred & $36 \pm 23$ & 25 & & & \\
\hline
\end{tabular}

EDSS: Expanded Disability Status Scale; NS: not significant $(\mathrm{p}>0.05)$. For further definitions see legend to table 1 . 
Table 5. - Neurological subsystem scores and pulmonary function tests

\begin{tabular}{|c|c|c|c|c|c|}
\hline & \multicolumn{4}{|c|}{ Pulmonary function $\%$ pred } & \multirow[b]{2}{*}{ p-value } \\
\hline & Mean \pm SD & $\mathrm{n}$ & Mean \pm SD & $\mathrm{n}$ & \\
\hline & \multicolumn{2}{|c|}{ Pyramidal <4 } & \multicolumn{2}{|c|}{ Pyramidal $\geq 4$} & \\
\hline $\mathrm{VC}$ & $84 \pm 21$ & 21 & $79 \pm 23^{\circ}$ & 30 & NS \\
\hline FEV1 & $74 \pm 15$ & 21 & $82 \pm 24$ & 30 & NS \\
\hline MEP & $36 \pm 14$ & 20 & $24 \pm 15$ & 30 & $<0.01$ \\
\hline \multirow[t]{2}{*}{ MIP } & $53 \pm 23$ & 20 & $39 \pm 28$ & 30 & $<0.05$ \\
\hline & \multicolumn{2}{|c|}{ Brain stem $<3$} & \multicolumn{2}{|c|}{ Brain stem $\geq \mathbf{3}$} & \\
\hline $\mathrm{VC}$ & $87 \pm 20$ & 34 & $69 \pm 22$ & 16 & $<0.01$ \\
\hline FEV1 & $81 \pm 21$ & 34 & $71 \pm 26$ & 16 & NS \\
\hline MEP & $34 \pm 15$ & 34 & $19 \pm 12$ & 16 & $<0.01$ \\
\hline \multirow[t]{2}{*}{ MIP } & $47 \pm 23$ & 34 & $37 \pm 24$ & 16 & NS \\
\hline & \multicolumn{2}{|c|}{ Mental $<2$} & \multicolumn{2}{|c|}{ Mental $\geq 2$} & \\
\hline $\mathrm{VC}$ & $89 \pm 19$ & 31 & $69 \pm 22$ & 20 & $<0.002$ \\
\hline FEV1 & $85 \pm 22$ & 31 & $68 \pm 21$ & 20 & $<0.01$ \\
\hline MEP & $32 \pm 16$ & 31 & $24 \pm 13$ & 19 & NS \\
\hline \multirow[t]{2}{*}{ MIP } & $51 \pm 25$ & 31 & $31 \pm 14$ & 19 & $<0.001$ \\
\hline & \multicolumn{2}{|c|}{ Cerebellar $<3$} & \multicolumn{2}{|c|}{ Cerebellar $\geq \mathbf{3}$} & \\
\hline $\mathrm{VC}$ & $88 \pm 16$ & 32 & $71 \pm 27$ & 17 & $<0.05$ \\
\hline FEV1 & $84 \pm 19$ & 32 & $71 \pm 25$ & 17 & NS \\
\hline MEP & $32 \pm 16$ & 32 & $24 \pm 15$ & 16 & NS \\
\hline \multirow[t]{2}{*}{ MIP } & $46 \pm 21$ & 32 & $41 \pm 27$ & 16 & NS \\
\hline & \multicolumn{2}{|c|}{ Sphincter $<3$} & \multicolumn{2}{|c|}{ Sphincter $\geq \mathbf{3}$} & \\
\hline $\mathrm{VC}$ & $85 \pm 21$ & 38 & $69 \pm 24$ & 13 & $<0.05$ \\
\hline FEV1 & $82 \pm 21$ & 38 & $68 \pm 23$ & 13 & NS \\
\hline MEP & $31 \pm 15$ & 38 & $23 \pm 17$ & 12 & NS \\
\hline \multirow[t]{2}{*}{ MIP } & $45 \pm 24$ & 38 & $41 \pm 21$ & 12 & NS \\
\hline & \multicolumn{2}{|c|}{ Sensory $<2$} & \multicolumn{2}{|c|}{ Sensory $\geq 2$} & \\
\hline $\mathrm{VC}$ & $83 \pm 20$ & 23 & $79 \pm 25$ & 28 & NS \\
\hline FEV 1 & $79 \pm 22$ & 23 & $74 \pm 26$ & 28 & NS \\
\hline MEP & $32 \pm 17$ & 22 & $24 \pm 12$ & 27 & NS \\
\hline \multirow[t]{2}{*}{ MIP } & $50 \pm 30$ & 22 & $43 \pm 18$ & 27 & NS \\
\hline & \multicolumn{2}{|c|}{ Visual $<2$} & \multicolumn{2}{|c|}{ Visual $\geq 2$} & \\
\hline $\mathrm{VC}$ & $89 \pm 20$ & 25 & $73 \pm 22$ & 17 & $<0.05$ \\
\hline FEV1 & $86 \pm 22$ & 25 & $70 \pm 21$ & 17 & $<0.05$ \\
\hline MEP & $35 \pm 16$ & 25 & $21 \pm 12$ & 17 & $<0.005$ \\
\hline MIP & $52 \pm 24$ & 25 & $36 \pm 20$ & 17 & $<0.05$ \\
\hline
\end{tabular}

NS: not significant $(\mathrm{p}>0.05)$. For further definitions see legend to table 1.

Table 6. - Duration of disease, pulmonary function and neurological disability scores

\begin{tabular}{|c|c|c|c|c|c|}
\hline & \multicolumn{4}{|c|}{ Duration of disease } & \multirow[b]{2}{*}{ p-value } \\
\hline & $\begin{array}{l}\geq 18 \text { yrs } \\
\text { Mean } \pm \text { SD }\end{array}$ & $\mathrm{n}$ & $\begin{array}{l}<18 \text { yrs } \\
\text { Mean } \pm \text { SD }\end{array}$ & $\mathrm{n}$ & \\
\hline $\mathrm{VC} \%$ pred & $75 \pm 26$ & 22 & $85 \pm 19$ & 27 & NS \\
\hline FEV1 $\%$ pred & $75 \pm 24$ & 22 & $80 \pm 21$ & 27 & NS \\
\hline$T \mathrm{~L}, \mathrm{CO} \%$ pred & $81 \pm 15$ & 18 & $87 \pm 17$ & 29 & NS \\
\hline MEP \% pred & $36 \pm 27$ & 22 & $44 \pm 27$ & 19 & NS \\
\hline MIP \% pred & $34 \pm 16$ & 22 & $27 \pm 12$ & 19 & NS \\
\hline EDSS score & $7.1 \pm 1.6$ & 19 & $6.0 \pm 1.9$ & 23 & $<0.05$ \\
\hline \multicolumn{6}{|l|}{ FSS score } \\
\hline Pyramidal & $3.7 \pm 1.2$ & 19 & $3.3 \pm 1.1$ & 29 & NS \\
\hline Brain stem & $1.9 \pm 0.9$ & 19 & $1.9 \pm 1.2$ & 29 & NS \\
\hline Mental & $1.6 \pm 0.6$ & 19 & $1.1 \pm 1.0$ & 29 & $<0.001$ \\
\hline Cerebellar & $2.2 \pm 0.9$ & 18 & $2.3 \pm 1.2$ & 28 & NS \\
\hline Sphincter & $2.2 \pm 1.6$ & 19 & $1.6 \pm 1.4$ & 29 & NS \\
\hline Sensory & $1.9 \pm 1.3$ & 19 & $2.0 \pm 1.6$ & 29 & NS \\
\hline
\end{tabular}

NS: nonsignificant; EDSS: Expanded Disability Status Scale; FSS: Functional Systems Score. For further definitions see legend to table 1.

less disabled group, with the exception of decreased MEP and MIP and a borderline increased RV.

The patients were also grouped according to two levels of disability based on the different neurological FSS: pyramidal $(<4$ or $\geq 4)$; brain stem $(<3$ or $\geq 3)$; men- tal $(<2$ or $\geq 2)$; cerebellar $(<3$ or $\geq 3)$; sphincter $(<3$ or $\geq 3$ ); visual $(<2$ or $\geq 2)$; and sensory $(<2$ or $\geq 2$ ) (table 5 ). In each functional system, a better pulmonary function was also noted in relation to the neurologically better score and several differences were significant. 
Duration of disease and relationship with pulmonary and neurological dysfunction

The average duration of MS from the time of diagnosis was $18 \pm 12$ (range 2-56) yrs. The patients were grouped according to two levels of disease duration: $<18$ and $\geq 18$ yrs (table 6 ). Although lung volume (VC, FEV1), TL,CO,sb, MEP and MIP tended to be higher in those with a shorter disease duration, the different was not significant. The EDSS score was positively correlated with disease duration. However, no significant difference was noted for the different functional systems of the FSS score, with the exception of mental status (which was worse in those with a longer duration of MS).

When the patients were subdivided into three groups with different disease duration (i.e. $\leq 10,11-<25$ yrs, $\geq 25 \mathrm{yrs}$ ) no significant differences were found in lung function indices between these groups.

\section{Discussion}

The aim of this study was to compare lung function and neurological disability status (EDSS, FSS) in multiple sclerosis (MS), and to relate these conditions to duration of disease. In general, the patients studied had moderately severe MS (EDSS $6.5 \pm 1.5$; mean FSS 1.33.4). Lung function was found to be only slightly abnormal, but MEP and MIP were markedly disturbed, and clearcut nocturnal $\mathrm{O}_{2}$ desaturation was detected. No significant correlation was found between lung function and duration of disease, which confirms the almost unpredictable course of the disease, with variable respiratory and muscular involvement.

Before discussing these results in detail, it should be remembered that performing a pulmonary function test can be quite labourious and stressful for MS patients. In general, patients with MS show a poor activity tolerance and often complain of fatigue [20, 21]. The MS patients in the present study mentioned this "fatigue symptom" quite often during pulmonary testing. In 25 of them (40\%), even a plethysmographic measurement of $R$ aw, TGV, TLC and RV was not possible, mainly because closure of the shutter was not tolerated, or sitting in the plethysmograph was impossible for orthopaedic reasons.

This study emphasizes, in particular, the prevalence of respiratory muscle dysfunction in MS patients (abnormal MEP in 98\%). Despite this marked respiratory muscle dysfunction, the MS patients rarely complained of pulmonary symptoms, such as cough or shortness of breath. The same remark has already been made in a study by SMeLtzer et al. [22]. They suggested that the fatigability is so pronounced in MS that fatigue rather than dyspnoea appears to be the limiting factor. In addition, impaired innervation of the upper airway may result in a diminished awareness of coughing.

The MEP and MIP might underestimate respiratory muscle force due to problems of co-operation. On the one hand, FIz et al. [23] stated that although three trials are sufficient for normal subjects to achieve adequate MEP and MIP measurements, as many as nine trials may be required in patients with respiratory diseases. On the other hand, too many recurrent trials may provoke fatigue. From our previous experiences in healthy subjects [14], patients with COPD [13], and patients with neuromuscular disease [15], we are confident that the present data for MEP and MIP are reliable. Thus, our data demonstrate true dysfunction of the respiratory muscles, which may be due to pathology in the corticospinal cord or to pathology in the brain stem, with interruption of the motor pathway to respiratory nerves (see below).

Expiratory muscle dysfunction, in particular, was common in this study group; whereas, the mean spirometric values were normal or only slightly lowered. MEP and MIP were often even reduced in patients with normal lung volumes. Other authors [21, 22, 24, 25] have also noted that occult respiratory muscle dysfunction is frequent in MS patients free from pulmonary symptoms or disease, as found in other neuromuscular diseases [15]. Indeed, even severe muscle dysfunction may be accompanied by little or no lung volume loss $[15,26$, 27]. The relationship between VC (\% pred) and MEP or MIP (\% pred) is known to be parabolic [28]. The decrease in VC is only small, as long as the MIP remains above $40 \%$ predicted.

The values of MIP and MEP found in the present study appeared to be lower than those in the study by SMELTZER and co-workers [22, 24], but similar to those found by FogLio et al. [25]. In the present study, the expiratory muscle weakness appeared to be more pronounced than that of the inspiratory muscles. SMELTZER and co-workers $[22,24]$ made the same observation, and explained that paralysis in advanced MS tends to ascend slowly from lower extremities to upper extremities. As a result, the first respiratory muscles to be affected are the abdominal muscles followed by the intercostal muscles. The diaphragm, which is innervated by the phrenic nerve may be expected to be the last to be affected.

In those patients with a restrictive (or mixed) disorder, we found significantly lower MIP and MEP values than in those with a normal pulmonary function. Thus, respiratory muscle dysfunction seemed to be the principal cause of restriction. The significant positive correlation between both MEP-MIP and VC-FEV1 supports this hypothesis.

Although, at entry, only two patients used bronchodilators, and although for the group as a whole the mean values for $\mathrm{FEV} 1 / \mathrm{VC}$ and $R$ aw were normal, there was evidence of an obstructive dysfunction in 19 patients $(31 \%)$. Smoking could be one explanation for this rather high incidence of obstructive dysfunction, in that 5 of these 19 patients were current or ex-smokers. Deficient airway clearing (secondary to MS and muscle weakness) could be another explanation.

A substantial number of nocturnal desaturators were also detected: 19 of the 27 patients tested (i.e. $70 \%$ desaturated below 92\%). No significant differences were found in the results of pulmonary function tests (FEV1, VC, TLC, TL,CO, MEP, MIP) between desaturators and nondesaturators. Nine of the 19 desaturators $(47 \%)$ even had a normal spirometry. Thus, the question arises why they desaturate during sleep. In the literature, several authors have noted a correlation between narcolepsy and MS (both narcolepsy and MS have been associated with the histocompatibility antigen human leucocyte antigen 
(HLA)-DR2) [26, 27, 29-31]. In general, patients do not desaturate due to narcolepsy. In the present study, 25 patients used sedative drugs, which might interfere with nocturnal ventilation.

Casuistic reports have demonstrated abnormalities of respiratory control in MS patients (paralysis of voluntary respiration, paralysis of automatic respiration, apnoeustic breathing), although these problems are generally observed only during acute exacerbations $[3,5,6,8-10$, 32]. Obstructive sleep apnoea has also been observed $[5,32]$. Bulbar dysfunction may predispose the patients to aspiration with desaturation, especially at night [32]. Further studies concerning breathing pattern during sleep and respiratory drive are needed.

We found a correlation between neurological disability and pulmonary dysfunction. In the neurologically more disabled group (with disability score $\geq 7$ ), significantly worse pulmonary function tests (VC, FEV1, PEF, MEF50) were found. Although the MEP and MIP were lower in the more disabled, the difference did not reach significance. Furthermore, in the study by FogLIO et al. [25] no significant relationship was found between MEP or MIP and EDSS. However, SMELTZER and co-workers [22] observed that MEP and MIP were significantly related to EDSS. These differences in results can be explained by the variable nature of MS. A patient can have a high disability score either due to muscle weakness (and hence respiratory dysfunction) or to cerebellar dysfunction (with little or no respiratory muscle weakness). Pathology in the corticospinal cord may produce not only paralysis of the limbs, but also weakness of the respiratory truncal muscles. It is, therefore, not surprising that in the present study, MIP and MEP were significantly different between those patients with versus those without a severe pyramidal syndrome. MS lesions in the brain stem can also interrupt the motor (reticulospinal) pathway to phrenic, intercostal and accessory respiratory muscle nerves. Therefore, it is not unexpected that MIP and MEP were more disturbed in those with a severe brain stem disorder than in those without (although the difference was only statistically significant for MEP). The higher MIP and MEP in those with less mental disturbance and the higher VC, MIP and MEP in those with less visual disturbance can be explained by better collaboration and co-ordination.

No statistically relevant correlation was found between duration of disease and the different FSS scores (with the exception of mental status), nor between duration of disease and lung function. We believe that this finding is due to the variable course of MS itself. A longitudinal follow-up study is planned to test this hypothesis.

In conclusion, respiratory dysfunction is common in MS patients, even in those patients with normal spirometric values. However, respiratory complaints are quite rare. There is a correlation between pulmonary dysfunction and the stage of neurological disability. Maximal static expiratory and inspiratory mouth pressure, in particular, appear to be correlated with the stage of pyramidal and brain stem disease. Desaturation at night is frequent, but does not appear to be correlated with pulmonary dysfunction. There is also no correlation between pulmonary dysfunction and duration of disease, due to the variable course of the disease.

\section{References}

1. Aisen M, Arlt G, Foster S. Diaphragmatic paralysis without bulbar or limb paralysis in multiple sclerosis. Chest 1990; 98: 499-501.

2. Balbierz JM, Ellenbergh M, Honet JC. Complete hemidiaphragmatic paralysis in a patient with multiple sclerosis. Am J Phys Med Rehab 1988; 67: 161-165.

3. Boor JW, Johnson RJ, Canales L, Dunn DP. Reversible paralysis of automatic respiration in multiple sclerosis. Arch Neurol 1977; 34: 686-689.

4. Cooper CB, Trend P St J, Wiles CM. Severe diaphragm weakness in multiple sclerosis. Thorax 1985; 40: 633-634.

5. Howard RS, Wiles CM, Hirsch NP, et al. Respiratory involvement in multiple sclerosis. Brain 1992; 115: 479-494.

6. Kuwahira I, Kondo T, Ohta Y, Yamabayashi H. Acute respiratory failure in multiple sclerosis. Chest 1990; 97 : 246-248.

7. La Ban MM, Taylor RS, Meerschaert JR. Relapsing hemiparetic diaphragm in multiple sclerosis (Letter). Arch Phys Med Rehab 1983; 64: 514.

8. Mochizuki A, Yamanouchi H, Murata M, et al. Medullary lesion revealed by MRI in a case of MS with respiratory arrest. Neuroradiology 1988; 30: 574-576.

9. Noda S, Umezaki H. Dysarthria due to loss of voluntary respiration (Letter). Arch Neurol 1982; 39: 132.

10. Yamamoto T, Imai T, Yamasaki M. Acute ventilatory failure in multiple sclerosis. J Neurol Sci 1989; 89: 313-324.

11. Poser CM, Scheinberg L, McDonald WI, et al. New diagnostic criteria for multiple sclerosis: guidelines for research protocols. Ann Neurol 1983; 13: 227-231.

12. Kurtzke JF. Rating neurological impairment in multiple sclerosis: an expanded disability status scale (EDSS). Neurol 1983; 33: 1444-1452.

13. Decramer M, Demedts M, Rochette F, Billiet L. Maximal transrespiratory pressures in obstructive lung disease. Bull Eur Physiopathol Respir 1980; 16: 479-490.

14. Vanmeenen MT, Demedts M, Vaerenbergh H, Ghesquere J. Transdiaphragmatic, esophageal and gastric pressures during maximal static inspiratory and expiratory efforts in young subjects: effects of manoeuvre and sex. Eur $J$ Respir Dis 1984; 65: 216-223.

15. Demedts M, Beckers J, Rochette F, Bulcke J. Pulmonary function in moderate neuromuscular disease without respiratory complaints. Eur J Respir Dis 1982; 63: 62-87.

16. ATS Statements. Standardization of spirometry - 1987 update. Single-breath carbon monoxide diffusing capacity (transfer factor). Am Rev Respir Dis 1987; 136: 1285-1307.

17. ERS Statement. Standardized lung function testing. Eur Respir J 1993; 6 (Suppl. 16): 1-100.

18. Standardized lung function testing: report working party. Standardization of lung function tests. Bull Eur Physiopathol Respir 1983; 19 (Suppl. 5): 1-95.

19. Rochester DF, Arora NS. Respiratory muscle failure. Med Clin North Am 1983; 67: 573-597.

20. Freal JE, Kraft GH, Goryell JK. Symptomatic fatigue in multiple sclerosis. Arch Phys Med Rehabil 1984; 65: $135-138$.

21. Olgiati R, Jacquet J, Di Prampero P. Energy cost of walking and exertional dyspnea in multiple sclerosis. Am Rev Respir Dis 1986; 134: 1005-1010.

22. Smeltzer SC, Utell MJ, Rudick RA, Herndon RM. Pulmonary function and dysfunction in multiple sclerosis. Arch Neurol 1988; 45: 1245-1249. 
23. Fiz JA, Monserrat JM, Picado C, Plaza U, Agusti-Vidal A. How many manoeuvres should be done to measure maximal inspiratory pressure in patients with chronic airflow obstruction? Thorax 1989; 44: 419-421.

24. Smeltzer SC, Skurnick JM, Troiano R, et al. Respiratory function in multiple sclerosis (utility of clinical assessment of respiratory muscle function). Chest 1992; 101: 479-484.

25. Foglio K, Clini E, Fachetti D, et al. Respiratory muscle function and exercise capacity in multiple sclerosis. Eur Respir J 1994; 7: 23-28.

26. Gal TJ, Arora NS. Respiratory mechanics in supine subjects during progressive partial curarization. J Appl Physiol: Respirat Environ Exercise Physiol 1982; 52: 57-63.

27. Poirier G, Montplaisir J, Dumont M, et al. Clinical and sleep laboratory study of narcoleptic symptoms in multiple sclerosis. Neurology 1987; 37: 693-695.

28. De Troyer A, Borenstein S, Cordier R. Analysis of lung volume restriction in patients with respiratory muscle weakness. Thorax 1980; 35: 603-610.

29. Rumbach L, Tongio MM, Warter JM, Collard M, Kurtz D. Multiple sclerosis, sleep latencies and HLA antigens. J Neurol 1989; 236: 309-310.

30. Schrader H, Gotlibsen OB, Skomedal GN. Multiple sclerosis and narcolepsy/cataplexy in a monozygotic twin. Neurology 1980; 30: 105-108.

31. Younger DS, Peckley TA, Thorpy MJ. Multiple sclerosis and narcolepsy: possible similar genetic susceptibility. Neurology 1991; 41: 447-448.

32. Carter JL, Noseworhty JH. Ventilatory dysfunction in multiple sclerosis. Clin Chest Med 1994; 15: 693-703. 